\title{
As transformações recentes no mercado de trabalho paranaense: uma aplicação do método shift-share
}

\author{
Carlândia Brito Santos Fernandes ${ }^{1}$ \\ Marina Silva da Cunha ${ }^{2}$
}

Resumo: O objetivo deste artigo é analisar o comportamento do emprego formal no Estado do Paraná, no período de 1996 até 2006. Com base nas informações da Relação Anual de Informações Sociais (RAIS) do Ministério do Trabalho (MTE), aplica-se o método shift share para captar as transformações do mercado de trabalho paranaense. Os resultados apontam uma expansão do mercado de trabalho formal paranaense no período, com destaque aos setores do comércio, que apresentou crescimento excepcional, e ao da indústria. Ressalta-se também o crescimento do emprego nas regiões não metropolitanas, principalmente na Oeste e Noroeste, superior ao da Região Metropolitana de Curitiba.

Palavras-chave: Emprego Formal; Mercado de trabalho; Paraná.

JEL: J21;R23

\footnotetext{
1 Professora Assistente do Departamento de Economia da Universidade Estadual de Maringá, e-mail: carlandiasan@hotmail.com.

2 Professora Associada do Departamento de Economia da Universidade Estadual de Maringá, e-mail: mscunha@uem.br.
} 


\title{
Recent transformations in Parana's labor market: an application of the shift-share method
}

\begin{abstract}
This article aims to analyze the behavior of formal employment in the State of Paraná, from 1996 up to 2006. Based information from the Department of Labors's (MTE) - Annual Relation of Social Information (RAIS), the shift method share is applied to capture the transformations on the labor market in Paraná. The results point out to a formal labor market expansion in Paraná, in the period, with prominence on the trade sections, that presented exceptional growth, and the industry. The emplyment growth in the non-metropolitan areas is also emphasized mainly in the West and Northwest, surpassing to the metropolitan area of Curitiba.
\end{abstract}

Keywords: formal employment; labor market; Paraná.

\section{Introdução}

As respostas internas à abertura da economia durante a década de 1990 possibilitaram ao Brasil certa reestruturação do setor produtivo, que trouxe para algumas regiões, de forma não sistemática, possibilidades de diversificação de suas atividades produtivas ou mesmo de intensificação das já existentes. Conforme Gremaud et al. (2007), no início da década de 2000, sem a valorização cambial, possibilitou-se um processo de substituição de importações em alguns segmentos. Assim, verificaram-se melhoras do saldo comercial e reduções gradativas na taxa de juros foram possíveis. Esses fatores, somados ao excelente desempenho do comércio mundial, induziram a retomada do investimento e se refletiram positivamente no nível de atividade econômica e, consequentemente, no mercado de trabalho.

O comportamento de emprego no Brasil no período recente pode ser dividido em duas fases, conforme Passos et al. (2005), Baltar et al. (2006), Ramos (2007) e Pochmann (2006). A primeira compreende quase toda a década de 1990, marcada pelas altas taxas de inflação e a insegurança das transformações econômicas e consequentemente fraco desempenho do mercado de trabalho. A segunda, a partir da liberalização cambial em 1999, aponta para um melhor desempenho da economia e como resultado uma maior geração de postos de trabalho.

Segundo Ramos (2007), o fraco desempenho do nível de emprego no Brasil, no último quadriênio da década de 1990 deveu-se ao fato de que a economia, recém inserida num processo de abertura comercial, passava por um processo de controle inflacionário baseado em política de valorização cambial, que, em conjunto com condições externas desfavoráveis, geravam incertezas e reprimia 
a demanda por trabalho. No entanto, a mudança no regime cambial no fim dessa década e as melhoras no cenário internacional passaram a incentivar a geração de novos postos de trabalho e propiciou um crescimento econômico significativo ao Brasil, no período de 1999 a 2005, chegando a uma média anual de $4,9 \%$.

Para Passos et al. (2005), enquanto na década de 1990 o mercado de trabalho formal brasileiro eliminou muitos postos de trabalho, especialmente a indústria, no início da década atual, notadamente após a mudança cambial de 1999, a capacidade de geração desses postos formais foi recuperada. Salienta que, no período 1992-2002, a queda da participação do emprego formal constituiu-se em um fenômeno apenas metropolitano e a participação dos trabalhadores com carteira no mercado de trabalho brasileiro foi estável.

Paralelamente, diferentes estudos sobre a economia paranaense apontam as boas perspectivas de desempenho do Estado, a partir de meados da década de noventa. Para Maia (2002), a partir de 1994, aumentaram as decisões de investimentos no Estado, levando a instalações de novas empresas, ampliações e modernizações, deixando de se caracterizar como exportador somente de produtos básicos. Vale salientar, conforme Lourenço (2005), que essa etapa de intensificação da diversificação e modernização do perfil produtivo, foi uma retomada daquela trilhada nos anos 1970 e interrompido nos anos 1980. A economia paranaense, de acordo com Macedo (2002), passa a apresentar um novo modelo de desenvolvimento baseado na inserção da dinâmica espacial da economia brasileira. O que foi possível com a intensidade e a natureza de novos investimentos ocorridos em tal período, sobretudo os realizados no setor automotivo. Conforme Trintin (2006), o Estado se aproveitou das oportunidades abertas pelo novo ciclo de investimentos e se empenhou em atrair novos investimentos, principalmente através da concessão de incentivos fiscais e financeiros, criando novas perspectivas de um Estado industrializado. Assim, com esse processo de transformação estrutural e com o crescimento qualitativo da indústria, alguns setores tornaram-se mais dinâmicos.

Assim, este trabalho tem como objetivo analisar o comportamento do mercado de trabalho no Estado do Paraná, neste contexto de transformações no cenário econômico brasileiro, com repercussões no seu mercado de trabalho, associadas a mudanças na estrutura produtiva do Estado do Paraná, notadamente a partir da segunda metade da década de 1990. As informações utilizadas são da Relação Anual de Informações Sociais (RAIS) do Ministério do Trabalho (MTE), que fornece um retrato do mercado de trabalho formal brasileiro.

Este trabalho está subdividido em três seções, além dessa introdução. $\mathrm{Na}$ próxima seção se faz uma breve apresentação da metodologia utilizada e uma análise descritiva das informações da RAIS/MTE. A seção seguinte analisa as transformações no mercado de trabalho do Estado, com base nos resultados do método shift-share. Por fim, a última seção é dedicada às considerações finais. 


\section{Metodologia}

\subsection{Método shift-share $e^{3}$}

Para acompanhar as transformações do mercado de trabalho paranaense, é utilizado o método shift-share (estrutural-diferencial), muito empregado em análises regionais, que descreve o crescimento econômico de determinada região, através da decomposição de seus fatores, com base em sua estrutura produtiva 4 .

O emprego total no Estado do Paraná, em todos os setores da atividade econômica, em cada instante de tempo pode ser representado por:

$E_{t}^{r}=\sum_{i} e_{i t}^{r}$

Em que,

$E_{t}^{r}=$ nível total de emprego formal no Estado do Paraná no instante $t$,

$e_{i t}^{r}=$ nível do emprego formal no setor $i$ da região $r$ no instante $t$.

Considerando $^{E_{i t}}$ o nível total de emprego formal no setor $i$ no instante $t e S_{i t}^{r}$ a fração do emprego formal total do setor $i$ no instante $t$ na região $r$, pode-se reescrever a equação (1), como segue,

$E_{t}^{r}=\sum_{i} S_{i t}^{r} E_{i t}$

Com isso, é possível obter o nível do emprego formal na região $r$ no tempo $t$, dada a distribuição setorial no instante de referencia $\bar{t}$, ou seja, $\bar{E}_{t}^{r}$,

$\bar{E}_{t}^{r}=\sum_{i} S_{i \bar{t}}^{r} E_{i t}$

Por fim, pode-se saber se uma determinada região ganhou ou perdeu postos de trabalho no período atual, mas considerando a estrutura de um período anterior, ou seja,

$\mathrm{D} E_{t \bar{t}}^{r}=\sum_{i}\left(S_{i t}^{r}-S_{i \bar{t}}^{r}\right) E_{i t}=E_{t}^{r}-\bar{E}_{t}^{r}$

3 Para maiores detalhes consulte Ramos (2007).

4 Lamarche et al. (2003: 121) afirmam que: "Shift-share analysis has become one of the most widely-used partitioning techniques in regional development studies since it was introduced by Prof. J. Harry Jones in The Royal Commission on the Distribution of the Industrial Population published in 1940". 
A partir dessas equações, pode-se efetuar a análise de "realocação espacial” e verificar, entre as regiões geográficas do Estado do Paraná, qual obteve maior (menor) ganho (perda) na geração de postos de trabalho, considerando dois instantes no tempo, e avaliar quais setores contribuíram de forma mais intensa (menos intensa) para o resultado.

\subsection{Análise descritiva preliminar}

Conforme salientado, neste trabalho são utilizadas as informações da Relação Anual de Informações Sociais (RAIS) do Ministério do Trabalho e Emprego (MTE), que coleta informações do estoque de trabalho formal ou com vínculo em 31 de dezembro de cada ano.

A evolução do emprego formal no Estado do Paraná, no período 1996-2006, está apresentada no gráfico 1, em que se verifica um crescimento do emprego, da ordem de 55,79\%, o que equivale a uma média anual de 4,5\% e um total de 806 mil postos de trabalho. A parte mais expressiva desse crescimento (30,35\%) coube ao período de 2002 a 2006, com a criação de aproximadamente 400 mil novas vagas de emprego. De 1996 até 1999, o crescimento foi de apenas 9,39\% e os restantes 16,04\% ocorreram entre 1999 e 2002.

Segundo IPARDES (2003), na década de 1990, a conjugação das decisões de abertura comercial, privatizações das empresas estatais, liberalização dos fluxos de capitais, estabilidade monetária mediante a valorização cambial, limitou dramaticamente as possibilidades de crescimento econômico num quadro de ausência, ou de políticas setoriais e regionais não sistemáticas. Além de tais decisões, a consequente intensificação do processo de reestruturação produtiva, implementado sobretudo pelas grandes empresas industriais, comerciais e de serviços contribuíram para a desestruturação do mercado de trabalho no País, gerando patamares mais elevados de desemprego e crescente precarização das relações de trabalho.

No final da década de 1990, apesar dos esforços efetuados pelo Estado do Paraná na captura de novos investimentos, o mercado de trabalho paranaense teve em média um desempenho modesto, seguindo a tendência nacional. 
GRÁFICO 1. TAXA DE VARIAÇÃO ANUAL DO EMPREGO NO PARANÁ, DE 1996 A 2006

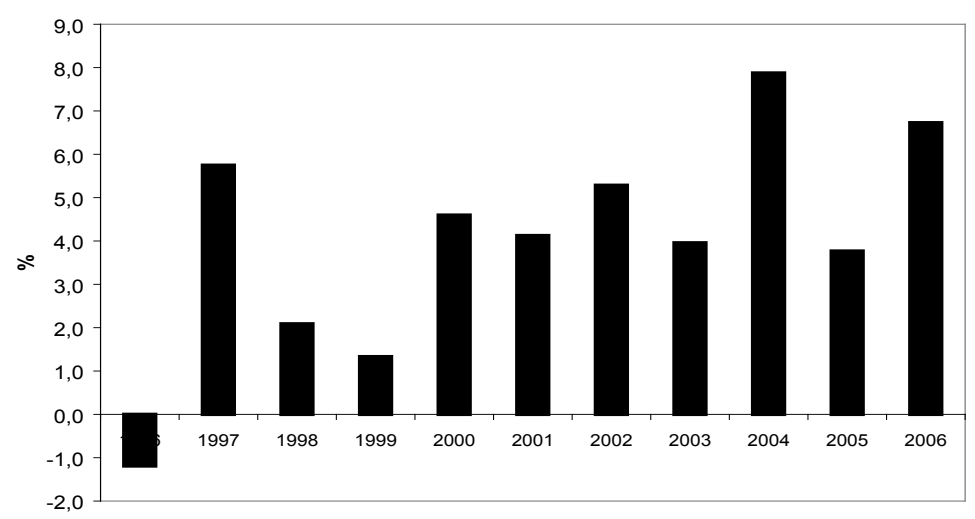

FONTE: elaboração própria com base em dados da RAIS/MTE.

O desempenho do mercado de trabalho no Estado do Paraná foi melhor no início da década de 2000. A título de ilustração, esse fato contribuiu para que o Estado chegasse à vice-liderança nacional no desenvolvimento municipal, segundo a Federação das Indústrias do Rio de Janeiro (FIRJAN). O Índice FIRJAN de Desenvolvimento Municipal (IFDM) deu ao Paraná nota o,8035, em uma escala que vai de zero a um, ficando atrás somente do Estado de São Paulo, considerando o período de 2000 a 2005. Dos 399 municípios paranaenses, nenhum foi considerado com baixo grau de desenvolvimento. Pelo IFDM 2005, o Paraná tem 17 cidades consideradas altamente desenvolvidas. A maior parte dos municípios do estado, 346, tem índice de desenvolvimento considerado moderado. Outros 36 têm o desenvolvimento regular. Maringá foi a cidade melhor colocada no Paraná, situada também como a $36^{\mathrm{a}}$ no ranking nacional. No Paraná, os municípios mais bem colocados, depois de Maringá, foram Londrina, Curitiba, Pinhais e Toledo. Curitiba ocupou o primeiro lugar no ranking de desenvolvimento entre as capitais brasileiras ${ }^{5}$.

O setor industrial, sempre considerado líder no processo de desenvolvimento econômico, contribuiu com a geração de quase 236 mil postos de trabalho no período, dos quais quase 168 mil foram gerados a partir de 2001, deixando claro que o final da década de noventa realmente inibiu a demanda por trabalho ${ }^{6}$.

5 Informações correspondem à notícia publicada em 13/08/o8 no site IPARDES URL:www.ipardes.gov. br

6 Embora a indústria tenha apresentado um crescimento de 72,3\% na geração de empregos, que foi um desempenho pior apenas que o do comércio, de $94,6 \%$, é importante evidenciar o seu efeito na economia. O que se dá não só por apresentar elevada demanda por matérias-primas e serviços, mas também por ser o setor responsável por grande parcela da renda. Destacam-se os sub-setores de elevado capital, como as montadoras de automóveis, que promovem empregos nos demais setores da economia e estimulam a capacitação tecnológica nas empresas locais e nos trabalhadores, melhorando o padrão social e de qualificação da sociedade. 
Dentre as 236 mil vagas geradas no setor industrial, quase metade se originou nos sub-setores de produtos alimentícios, bebidas e álcool etílico e do subsetor da indústria têxtil.

Esse desempenho no mercado de trabalho da indústria no Estado vincula-se, em grande medida, à conjuntura econômica nacional, que favoreceu o consumo interno, e à conjuntura internacional, apoiada, especialmente, pela política cambial adotada pelo governo brasileiro, notadamente entre os anos de 1999 e 2003, que gerou ganho de competitividade ao setor devido à desvalorização da moeda nacional (Maranho 2008)7 .

O setor do comércio, que apresentou o maior crescimento percentual no período, garantiu a geração de 220 mil vagas de emprego, sendo que mais de $80 \%$ dessas vagas surgiram entre 2000 e 2006. A liderança do setor comércio explica-se pela expansão da demanda por bens de consumo após o Plano Real, ou seja, o comércio sofre os reflexos diretos do ritmo do nível de renda e emprego.

Segundo Lemos et al. (2002), as grandes mudanças no panorama do comércio na década de 1990, destacando-se a concentração do setor, com a aquisição das pequenas e médias redes pelos grandes grupos, o aumento da competição, a entrada de grupos estrangeiros de varejo e o fim dos ganhos com a inflação, levaram as empresas a modernizarem e redimensionarem o tamanho de suas lojas, implementando novos sistemas de gestão e logística.

Para Gremaud et al. (2007), o desempenho na geração de empregos no comércio, principalmente nos anos 2000, explica-se pela expansão do consumo das famílias, no governo Lula. Para os autores, houve uma expansão do crédito para pessoa física devido à estabilidade da economia e uma série de medidas voltadas ao melhor desempenho do sistema de crédito, principalmente os voltados às pessoas de menor renda. Destacam-se a bancarização da população de baixa renda com o Banco Popular, políticas voltadas para o microcrédito e incentivo às cooperativas de crédito e medidas voltadas para a redução de risco, como o crédito consignado.

A estabilidade econômica, com a derrubada do imposto inflacionário e dos juros nominais, permitiu uma expansão da demanda, resultante inclusive da expansão de diversos mercados consumidores, de eletrodomésticos, por exemplo, decorrente da entrada de segmentos da população de menor renda, que até então lhe eram alheios (Passos et al., 2005).

Os setores de serviços e ensino também apresentaram bom desempenho no período e juntos foram responsáveis pela criação de quase 250 mil vagas de emprego no Estado do Paraná. O setor de serviços tem grande nível de heterogeneidade devido à diversidade de atividades que engloba.

7 Destaca-se na conjuntura internacional o desempenho da China, com crescimento do seu produto em aproximadamente $10 \%$ ao ano, aquecendo a demanda mundial. 
Os setores de administração púbica e agropecuária tiveram desempenhos menos expressivos na geração de postos de trabalho, ficaram bem abaixo dos 50\% de crescimento no período de 1996 a 2006. A agropecuária foi o único setor com desempenho melhor nos últimos anos da década de 1990, se comparado com os primeiros anos da nova década, afetados pela crise de renda e do endividamento dos produtores rurais. O crescimento do emprego no setor foi de $16 \%$, entre os anos 1996 e 1999, ou seja, de quase 15 mil vagas de emprego geradas no período analisado, cerca de 80\% dessas vagas surgiram no final da década de 1990. Não obstante, a geração de empregos nesse setor sofre declínio nos primeiros anos do novo milênio. Alguns fatores podem ser citados para explicar esse desempenho, tais como: a mecanização e modernização das técnicas agrícolas, os baixos preços no mercado internacional de alguns produtos e a quebra da safra em decorrência de estiagem. A agricultura no Paraná caracteriza-se por atividades diversificadas, destacando-se a soja, o milho, o trigo e cana-de-açúcar. O Estado é um dos principais produtores de grãos do país, com a utilização de avançadas técnicas de cultivo e os maiores índices de produtividade.

O setor da construção civil foi o único que apresentou retração entre 1996 e 2006, entre os fatores determinantes desse comportamento pode ser citado o nível da taxa de juros, que apesar de ter sido reduzido no período estudado, ainda era um dos maiores do mundo, inibindo os investimentos no setor.

O gráfico 2, que desagrega o nível de emprego em termos regionais, indica que a Região Metropolitana de Curitiba gerou menos postos de trabalho que a Região Não Metropolitana, no período estudado. Em 1995, a Região Metropolitana de Curitiba tinha 683.447 postos de trabalho formal, e, em 2006, um total de 1.011.570, a Região Não Metropolitana detinha um total de 761.616 e 1.239.720, respectivamente. Verifica-se que aproximadamente 40\% das novas vagas, ou cerca de 300 mil vagas, foram geradas na Região Metropolitana de Curitiba (RMC), enquanto que mais de 60\% foram criadas no Paraná não metropolitano. Situação similar à apontada por Ramos (2007), em que a expansão do emprego formal no Brasil não metropolitano foi de 48,6\% e do metropolitano foi de 23,6\%, no período de 1995 a 2005.

Há, no Estado do Paraná, nove mesorregiões, além da Metropolitana de Curitiba, são elas: Centro Ocidental, Norte Central, Norte Pioneiro, CentroOriental, Oeste, Sudoeste, Centro-Sul, Sudeste e Noroeste. Em 2006, essas regiões respondiam, respectivamente, por 3,9\%, 34,7\%, 6,7\%, 10,6\%, 18,5\%, $6,3 \%, 5,6 \%, 4,1 \%$ e $9,9 \%$ do total de postos de trabalho protegidos na Região Não Metropolitana.

Desse modo, merece destaque a Região Norte Central, que depois da Região Metropolitana, em números absolutos, de 1996 até 2006, foi aquela que mais contribuiu com a geração de novas vagas de emprego no Estado; foram 161.730, quase um quarto de todas as vagas geradas no Paraná. A explicação está no fato dessa região ter em seu território duas das cidades mais populosas 
do Estado: Londrina e Maringá. Além disso, estão entre as cidades da região não metropolitana que mais contribuem ao $\mathrm{PIB}^{8}$ do Estado.

GRÁFICO 2. EVOLUÇÃO DO EMPEGO NAS REGIÕES METROPOLITANA E NÃO METROPOLITANA NO PARANÁ, DE 1996 A 2006

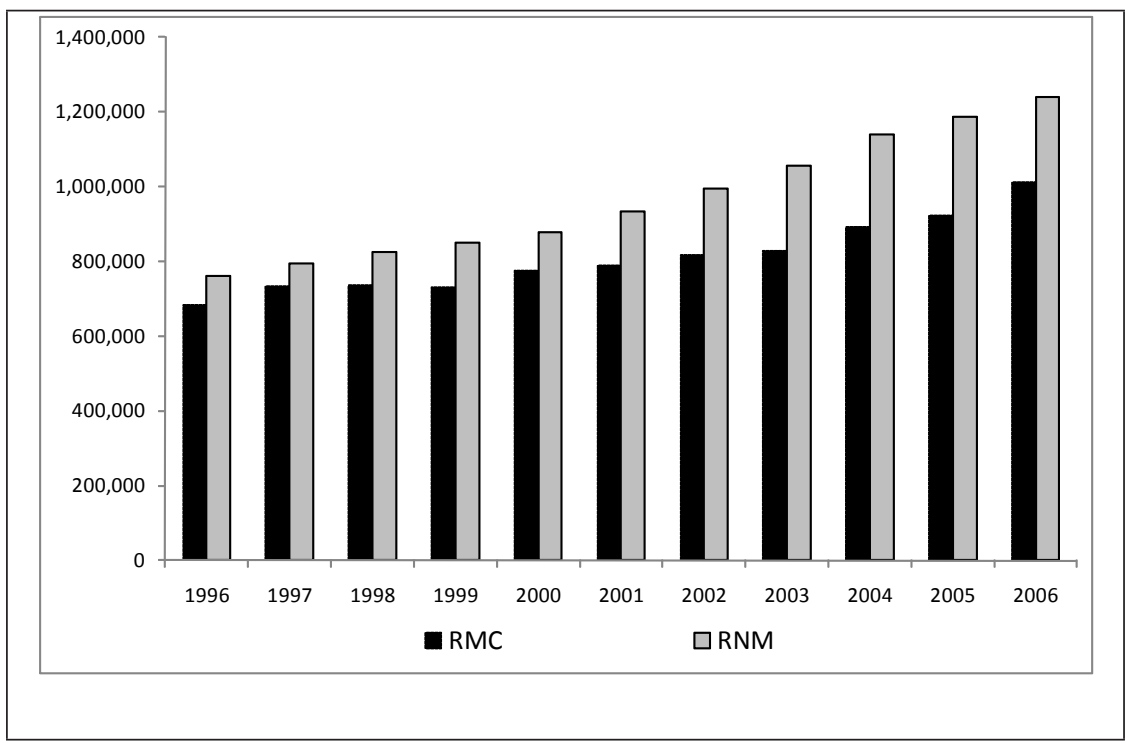

FONTE: elaboração própria com base em dados da RAIS/MTE.

A Região Oeste Paranaense, que inclui as cidades de Foz do Iguaçu, Cascavel e Toledo, ficou com a segunda posição em termos de crescimento do nível de empregos formais no grupo Não Metropolitano no período estudado, ou seja, gerou 102.604 postos de trabalho. De acordo IPARDES (2008), a justificativa está na concentração de vários estabelecimentos industriais nessa região, que foram responsáveis por 55,80\% de todo o valor adicionado fiscal industrial da região, no ano de 2005. O destaque cabe à indústria de alimentos, distribuída entre abate de animais e fabricação de produtos alimentícios e bebidas.

A seguir é realizada uma análise mais detalhada da evolução do emprego na Região Metropolitana de Curitiba, e nessas mesorregiões que compõem a Região Não Metropolitana, com base na metodologia shift-share. São considerados os principais setores econômicos: Indústria, Construção civil, Comércio, Serviços, Ensino, Administração Pública e Agropecuária.

8 No ano de 2006, Londrina e Maringá foram responsáveis por 8,6\% do PIB do Paraná, conforme IPARDES (2008). 


\section{Realocações espaciais do emprego formal}

Inicialmente, na tabela 1, observa-se a realocação do emprego nas regiões Metropolitana e Não Metropolitana do Paraná. Foi considerado tanto o ano de 2006, com base na estrutura ocupacional de 1996, quanto três sub-períodos: 1996-1999 ou período inicial (na década de 1990), 1999-2002 ou período intermediário (final da década de 1990 e início da de 2000) e 2002-2006 ou período final (no período mais recente). Essa análise por sub-períodos é relevante para se detectar mudanças na trajetória de cada localidade e de cada setor, que não necessariamente foi homogênea ao longo do período estudado.

Verifica-se que as mudanças para o conjunto das regiões geográficas foram no sentido de realocar postos de trabalho das regiões Centro-Ocidental, Norte Pioneiro, Sudoeste e Metropolitana de Curitiba para as demais, especialmente para as regiões Oeste e Noroeste, as quais absorveram aproximadamente $89 \%$ dessas vagas.

TABELA 1. EFEITO REALOCAÇÃO ESPACIAL DO EMPREGO, PARANÁ, 19962006.

\begin{tabular}{lr|r|r|r}
\hline Período & $1999-1996$ & $2002-1999$ & \multicolumn{1}{c}{$2006-2002$} & \multicolumn{1}{c}{$2006-1996$} \\
\hline Região Metropolitana de Curitiba & $-12.493,34$ & $-22.240,36$ & $2.610,36$ & $-44.286,78$ \\
Região Não-Metropolitana & & & & \\
Centro-Ocidental & $-1.430,00$ & $-1.526,86$ & $-1.333,61$ & $-5.199,72$ \\
Norte Central & $5.075,11$ & $5.419,48$ & $-10.754,98$ & $3.413,30$ \\
Norte Pioneiro & 203,67 & $-1.254,17$ & $-524,39$ & $-2.169,80$ \\
Centro Oriental & $-1.853,01$ & $2.447,52$ & 586,29 & $1.498,95$ \\
Oeste & $6.535,72$ & $6.854,75$ & $9.401,03$ & $28.714,34$ \\
Sudoeste & $-11.741,64$ & $3.665,89$ & $4.980,55$ & $-6.745,87$ \\
Centro-Sul & $1.638,53$ & $3.697,80$ & $-7.011,75$ & 217,07 \\
Sudeste & $6.636,49$ & $-2.872,31$ & $-4.612,84$ & $1.324,99$ \\
Noroeste & $7.428,47$ & $5.808,26$ & $6.659,33$ & $23.233,52$ \\
\hline
\end{tabular}

FONTE: elaboração própria com base em dados da RAIS/MTE. 
Para o ano de 1999, considerando a estrutura de empregos de 1996, as regiões que mais perderam vagas no mercado de trabalho foram a Metropolitana de Curitiba e a Sudoeste, sendo que as regiões que ampliaram suas vagas foram a Noroeste, a Sudeste e a Oeste, que acolheram mais de 21 mil postos de trabalho, do total de 27.517. No ano de 2002, em relação ao ano de 1999, entre os quase 28 mil postos de trabalho perdidos na Região Metropolitana de Curitiba, percebe-se que, paralelamente, houve uma criação de novos postos de trabalho nas regiões Noroeste, Oeste e Norte Central. Analisando o período mais recente, de 2002 até 2006, as regiões que tiveram as maiores perdas líquidas foram a Norte Central, a Centro-Sul e a Sudeste; e as regiões que obtiveram maiores ganhos líquidos de postos de trabalho foram a Oeste, a Noroeste e a Sudoeste. 


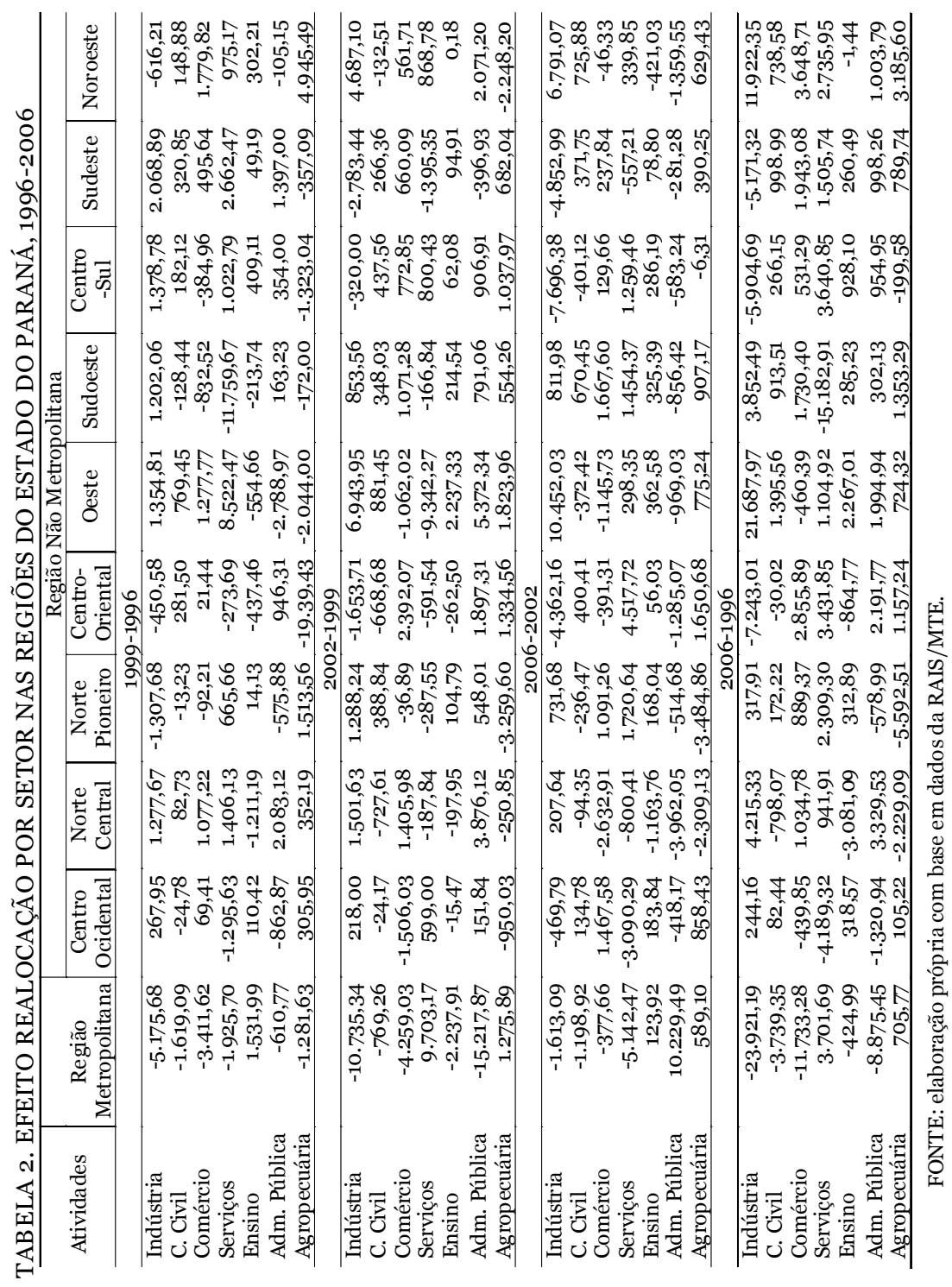


Assim, nota-se que a Região Metropolitana de Curitiba foi líder em perdas de postos de trabalho nos períodos iniciais da análise, de 1996 para 1999 e de 1999 para 2002. Constata-se que o segundo sub-período (1999-2002) foi aquele em que o mercado de trabalho formal da Região Metropolitana de Curitiba teve o pior desempenho. No entanto, de 2002 para 2006, essa região tem um resultado positivo, ampliando seus postos de trabalho.

Considerando o único período no qual a Região Metropolitana de Curitiba obteve ganho líquido de vagas de emprego, isto é, 2006, com a estrutura de empregos de 2002, percebe-se que os setores que contribuíram para tal resultado foram o da administração pública, da agropecuária e de ensino, conforme a Tabela 2, que permite observar além das relações inter-regionais as inter-setoriais. Porém, nos outros períodos, essa mesma região sofreu perdas significativas de postos de trabalho, notadamente nos setores industrial e comercial. Como exemplo, no período completo, o setor industrial foi responsável pela geração de quase 24 mil postos de trabalho nas áreas não metropolitanas, número que representa mais da metade do efeito total.

Na Região Não Metropolitana, destaca-se a Região Oeste, onde se verifica que o ritmo de criação de empregos protegidos foi mais intenso no período analisado. No período completo, o setor industrial dessa região foi responsável pelo ganho de 21.687 vagas de emprego. Conforme IPARDES (2008), a agroindústria é a grande responsável pela geração de postos de trabalho nessa região, cujos atrativos locacionais, desde o início do processo de industrialização do Estado do Paraná, estão ligados, basicamente, à oferta de matérias-primas agropecuárias ${ }^{9}$.

Os estudos sobre possibilidades e oportunidades industriais das décadas de 1960 e 1970, que apontavam a agroindústria da Região Oeste como estratégia de desenvolvimento industrial, foram reafirmados na década de 1990. Tanto que, entre 1985 e 2005 a participação da região no número de empregos industriais formais do Estado se elevou de 5,88\% para 10,23\%. São sete os segmentos industriais importantes no número de empresas e de empregos gerados no Estado, que juntos responderam, em 2005, por 52,91\% do número de empregos, e por 59,37\% do número de estabelecimentos (IPARDES 2008) $)^{10}$.

9 Entre as mais importantes empresas da Região Oeste, encontra-se a Sadia, que iniciou suas atividades em Toledo no final da década de 1950 (IPARDES 2008).

10 Fabricação de Produtos Alimentícios e Bebidas; Reciclagem; Preparação de Couros e Fabricação de Artefatos de Couros, Artigos de Viagem e Calçados; Confecção de Artigos do Vestuário e Acessórios; Fabricação de Produtos Têxteis; Fabricação de Móveis e Indústrias Diversas; e Fabricação de Produtos de Metal- Exclusive Máquinas e Equipamentos. (IPARDES 2008) 
Considerando o ano de 1999, com a estrutura ocupacional de 1996, o setor de serviços foi o responsável pela maior parte dos ganhos de postos de trabalho na Região Oeste. No entanto, no ano de 2002 com estrutura de 1999, tal setor eliminou mais de 9 mil postos de trabalho, mas os demais setores, com exceção do comércio, apresentaram ganhos, com destaque para a indústria e a administração pública. No ano de 2006, com a estrutura de 2002, pode-se afirmar que o setor industrial dessa localidade gerou postos de trabalho, em número suficiente, para compensar as vagas perdidas em outras regiões.

A Região Noroeste, que inclui os polos de Umuarama e Paranavaí, também se destaca na criação de postos de trabalho protegidos na Região Não Metropolitana, e, novamente, o setor industrial foi o de melhor desempenho ${ }^{11}$. No primeiro sub-período, de 1999 com estrutura de 1996, a agropecuária foi o setor que mais contribuiu para os ganhos de postos de trabalho. Por outro lado, nos outros dois sub-períodos, de 2002-1999, 2006-2002, e no período completo, a indústria se destaca na geração de empregos formais.

Segundo IPARDES (2004), entre 1995 e 2002 houve um expressivo aumento no número de empresas do parque industrial da Região Noroeste, passou de 1.195 para 2.211. O setor se divide em dois grandes grupos, o primeiro, da agroindústria, que se constitui por empresas que industrializam a cana de açúcar, bovinos, aves, mandioca e laranja. O segundo grupo, o de confecções, que forma um polo de referência nacional. A produção de açúcar e álcool é beneficiada pelas características climáticas da região, que é detentora da maior área plantada de cana de açúcar do Paraná ${ }^{12}$. No que diz respeito ao polo de vestuário e confecções, seu parque industrial cresceu de 277 confecções em 1995, para 763 em 2002, sendo que as mais importantes estão na cidade de Cianorte, onde se concentram também grandes shoppings atacadistas.

De acordo com IPARDES (2006), o parque industrial da mandioca, na microrregião Paranavaí-Loanda, é um dos maiores polos produtores nacionais do setor, sendo que a maioria das empresas produz farinha de mandioca e são conhecidas como farinheiras. A participação do setor no total de empregos na região aumentou de 7,99\% em 1995 para 10,44\% em 2002. Outro destaque cabe à indústria de metais sanitários de Loanda e região, que avançou de 85 postos de trabalho formais em 1995, para 602 em 2002 e 868 em 2004.

\footnotetext{
11 A Região Noroeste paranaense apresentou o melhor índice de crescimento de 1996 a 2006, mais de 90\%, representando uma média anual de 6,62\%, superior à do Estado. A maior parcela desse crescimento originou-se dos setores industrial e comercial, que expandiram em $130 \%$ os postos de trabalho no período. Mais de $80 \%$ das 26.742 mil novas vagas criadas pelo setor industrial nessa região foram geradas nos sub-setores da indústria têxtil e da indústria de produtos alimentícios, de bebida e álcool etílico. O setor comercial gerou 12.049 mil postos de trabalho no período em questão, sendo que 10.893 mil foram gerados no comércio varejista.
}

12 O crescimento desse segmento foi beneficiado pela a difusão de motores para veículos flex-fuel e pelo desenvolvimento do mercado internacional do etanol. 
As demais mesorregiões da Região Não Metropolitana, não tiveram um desempenho no mercado de trabalho tão próspero quanto às regiões Oeste e Noroeste. As sete mesorregiões restantes podem ser subdivididas em quatro grupos. No primeiro grupo, com desempenho positivo nos dois primeiros períodos e negativo apenas no último, estão as regiões Norte-Central e CentroSul. Entre 2006-2002, a Região Norte-Central perdeu, entre seus diferentes setores, mais de 10 mil postos de trabalho, sendo a administração pública o de maior baixa, seguida pelo comércio. Porém, no período completo o saldo de geração de postos de trabalho na região foi positivo, principalmente em função dos setores da indústria e administração pública. Na Região Centro-Sul, a migração de mais de 7 mil postos de trabalho no último sub período ocorreu, principalmente, em função do setor industrial. No período completo, de 1996 até 2006, os resultados indicam que a região não apresentou mudanças significativas no seu mercado de trabalho, pois o ganho foi de pouco mais de duzentas vagas de emprego.

No segundo grupo estão as regiões Centro-Oriental e Sudoeste, que reduziram o nível de emprego formal no primeiro quadriênio, mas o ampliaram nos dois quadriênios subsequentes. As perdas de postos de trabalho da Região Centro-Oriental, onde se destacam Telêmaco Borba e Ponta Grossa, podem ser atribuídas, especialmente, à agropecuária. No período completo, a região obteve ganhos de postos de trabalho, devido ao bom desempenho dos serviços, comércio e administração pública. A Região Sudoeste, composta pelas microrregiões de Capanema, Francisco Beltrão e Pato Branco, foi a que apresentou maior número de perdas entre as não metropolitanas. No primeiro período, o setor de serviços foi o principal responsável pela eliminação de postos de trabalho. No período analisado essa região obteve mais de 6700 perdas no mercado de trabalho devido, exclusivamente, à contribuição negativa do setor de serviços. Assim, verifica-se que enquanto a Região Centro-Oriental consegue um resultado positivo na criação de empregos protegidos no período estudado, a Região Sudoeste tem um saldo líquido negativo.

As regiões Sudeste e Norte Pioneiro formam o terceiro grupo e foram fontes de migração de emprego formal nos últimos dois sub-períodos, de 1999-2002 e 2002-2006, mas enquanto a primeira apresentou um saldo positivo ao final do período, de 1996-2006, a segunda contabilizou um resultado negativo. A Região Sudeste apresentou um ganho de postos de trabalho no ano de 1999 com estrutura de 1996, porém, nos sub períodos 2002/1999 e 2006/2002, o número de perdas de postos de trabalho superou aqueles que haviam sido gerados no final da década de 1990. No período completo, o desempenho da região foi de ganho de mais de 1.300 postos de trabalho e só não foi melhor devido ao setor industrial que eliminou mais de 5 mil vagas no mercado de trabalho formal. A Norte-Pioneiro, no primeiro período de análise, obteve ganhos de postos de trabalho, com destaque para a agropecuária. Em contraposição, no segundo e terceiro períodos, este setor foi o responsável por muitas perdas de postos de trabalho. Percebe-se, também, o baixo desempenho da 
agropecuária no período completo, contribuindo com mais de 5.500 perdas de postos de trabalho na região.

Por fim, o quarto grupo é constituído pela Região Centro-Ocidental com perdas de postos de trabalho em todos os períodos, sendo o setor de serviços o seu maior responsável, seguido pela administração pública e o comércio. Esse resultado corrobora com o encontrado por IPARDES (2004a), segundo o qual essa mesorregião teve uma das maiores taxas de desemprego no Estado e redução de seu mercado de trabalho formal, inclusive em Campo Mourão, seu principal município, no período 1996-2001 ${ }^{13}$. Conforme esse mesmo estudo, essa região, com a menor população entre as dez mesorregiões paranaenses, sofreu um processo de esvaziamento populacional, em que, em 2000, tinha 2/3 daquela residente em 1970.

Com isso, os resultados da análise shift-share permitem concluir que, considerando a estrutura de empregos de 1996, a Região Metropolitana de Curitiba perdeu postos de trabalho, especialmente nos setores da indústria e do comércio. Por outro lado, esses setores têm um melhor desempenho na Região Não Metropolitana.

A indústria se destaca na Região Oeste, absorvendo a grande maioria dessas novas vagas, mas nas regiões Noroeste, Norte Central e Sudoeste também há um crescimento desse setor. Por sua vez, o comércio tem bom desempenho nas regiões Noroeste, Sudoeste, Sudeste, Centro-Oriental e Norte-Central. Verificou-se que as regiões Oeste e Noroeste foram as únicas com saldo positivo de emprego em todos os sub-períodos analisados, indicando uma fase de crescimento econômico favorável.

Portanto, se, por um lado, na Região Metropolitana, onde há predominância das indústrias de elevado e médio índice tecnológico (como as montadoras de veículos), a indústria perdeu postos de trabalho, certamente contribuiu com aumento da renda e consequentemente com a geração de postos de trabalho em outros setores, como no de serviços. Por outro, gerou muitos postos de trabalho no interior do Estado, sobretudo nas indústrias com um menor nível tecnológico e mais intensivas em mão de obra, como a de alimentos, a têxtil e a sucroalcoleira.

13 O estudo aponta que a mesorregião foi a única em que nenhum setor industrial apresentou um crescimento significativo do emprego no período. Ademais, em relação ao Índice de Desenvolvimento Humano Municipal (IDHM), em 2000, nenhum município dessa região alcançou o valor médio para o Estado $(0,787)$, refletindo o alto percentual de famílias consideradas pobres (32\%). 


\section{Considerações finais}

Os resultados deste trabalho sugerem que o mercado de trabalho formal paranaense, ao longo do período de 1996 até 2006, passou por dois momentos distintos, seguindo a tendência nacional. Inicialmente, no final da década de 1990, apesar do saldo positivo na geração de emprego formal, o mercado de trabalho do Estado teve um desempenho modesto, mas, na década seguinte, o ritmo de crescimento do emprego formal é mais expressivo.

As condições macroeconômicas nesse período são favoráveis à evolução nos índices de emprego, merecendo destaque o fim das taxas de inflação muito elevadas, a consolidação do processo de abertura econômica, a retomada do crescimento da economia mundial e a depreciação cambial, que abriram novos horizontes aos investimentos produtivos e asseguraram maior tranquilidade aos investidores estrangeiros.

Nesse período, a Região Metropolitana de Curitiba reduz de modo relativo sua proporção nos postos de trabalho formal no Paraná. Assim, considerando os resultados da análise da realocação do emprego pelo método shift-share, pode-se dizer que a metrópole constitui-se em uma fonte de migração de postos de trabalho para a Região Não Metropolitana. Contudo, embora tenha apresentado um resultado inferior ao da Região Não Metropolitana, no período estudado, no período mais recente, a Região Metropolitana de Curitiba experimentou um melhor desempenho, com ganho de empregos protegidos.

No interior do Estado, destacam-se as regiões Oeste e Noroeste, onde o setor propulsor na geração de postos de trabalho foi o industrial, com ênfase na agroindústria, como é o caso das usinas de açúcar e álcool e farinheiras na Noroeste e dos abatedouros na Oeste. Por outro lado, a Região Centro-Ocidental teve o pior desempenho ao longo do período, com perda de emprego em todos os sub-períodos analisados. Vale destacar que embora a Região Sudoeste tenha alcançado a maior perda de postos trabalhos, entre 1996 e 2006, vem se recuperando na década de 2000.

Assim, os resultados sugerem que houve uma despolarização industrial, com uma realocação do emprego para o interior do Paraná, onde se verifica a criação de postos de trabalho formal, especialmente na indústria de produtos alimentícios, bebida e álcool etílico e da indústria têxtil. O crescimento do emprego no comércio, que também gerou muitos postos de trabalho no interior do Estado, pode ser explicado pela ampliação do volume de renda em função do desempenho industrial, ampliando o consumo, os shoppings atacadistas de confecções de Cianorte se constituem em um bom exemplo. Destaca-se ainda o setor de serviços que foi o único que gerou mais postos de trabalho na Região Metropolitana de Curitiba do que na Região NãoMetropolitana, o que se explica pela diversificação das atividades públicas e privadas nessa localidade e pelo adensamento populacional, que demanda 
uma maior estrutura de serviços.

Vale salientar que o crescimento do mercado de trabalho no interior do Paraná é importante para amenizar as pressões socioeconômicas na Região Metropolitana de Curitiba, que tem problemas com o esgotamento de sua capacidade de absorção do fluxo populacional intraestadual, tais como de infraestrutura básica, de violência e de pobreza.

\section{Referências}

ALVES, L. R. A. \& SHIKIDA, P. F. A. R. (2001). "Fontes de Crescimento das Principais Culturas do Estado do Paraná (1981-1999)”. Revista Paranaense de Desenvolvimento, Curitiba, 101(jul/dez): 17-32.

BALTAR, P. \& KREIN, J. D. \& MORETTO, A. (2006). "O emprego formal nos anos recentes”. Carta Social e do Trabalho. URL: http://www.eco.unicamp.br/ pesquisa/cesit/index.php. Acesso em: 17 de agosto 2009.

GREMAUD, A. P. \& VASCONCELLOS, M. A. S. \& JÚNIOR, R. T. (2007). Economia Brasileira Contemporânea. São Paulo: Atlas S.A

HAYNES, K.E. \& DINC, M. (1997). "Productivity change in manufacturing regions: a multifactor/shift-share approach". Growth and Change 28(2):201-211.

INSTITUTO PARANAENSE DE DESENVOLVIMENTO ECONÔMICO E SOCIAL IPARDES: Notícias. URL: http://www.ipardes.gov.br. Acesso em: 16 de agosto 2008.

. (2003). "Paraná - Diagnóstico Social e Econômico.” URL: www.ipardes. gov.br. Acesso em: 02 de junho 2009.

. (2004). "Leituras Regionais: Mesorregião Geográfica Noroeste Paranaense.” URL: http://www.ipardes.gov.br. Acesso em: 21 de julho 2009.

. (2004a). "Leituras Regionais: Mesorregião Geográfica Centro-Ocidental.” URL: http://www.ipardes.gov.br. Acesso em: 21 de julho 2009.

.(2005) “Os Vários Paranás: Estudos Socioeconômico-Institucionais Como Subsídio aos Planos de Desenvolvimento Regional.” URL : http://www.ipardes. gov.br. Acesso em: 02 de junho 2009.

. (2006a). "APLs do Estado do Paraná. Arranjo Produtivo Local de Metais Sanitários de Loanda e Região. Estudo de Caso.” URL : http://www.ipardes. gov.br. Acesso em: 21 de julho 2009.

. (2006b). “APLs do Estado do Paraná. Arranjo Produtivo Local da Mandioca da Região de Paranavaí-Loanda. Nota Técnica.” URL : http://www.ipardes.gov. br. Acesso em: 21 de julho 2009.

. (2007). "Dinâmica Recente da Indústria Paranaense: Estrutura e Emprego.” URL: http://www.ipardes.gov.br. Acesso em: 25 de março 2010.

. (2008). "Os Vários Paranás. Oeste Paranaense: o $3^{\circ}$ Espaço Relevante Especificidades e Diversidades.” URL : http://www.ipardes.gov.br. Acesso em: O2 de junho 2009. 
LAMARCHE, R. H. \& SRINATH, K. P. \& RAY, D. M.(2003). “Correct partitioning of regional growth rates: improvements in shift-share theory .(The Contributions of the Ray-Srinath Model)". Canadian Journal of Regional Science 26(1): 121-144.

LEMOS, M. L. F. \& ROSA, S. E. S. \& TAVARES, M. M. (2002).“Os Setores de Comércio e de Serviços”. BNDES Setorial (dez).

LOURENÇO, G.M. (2005). "Economia Paranaense: rótulos históricos e encaixe recente na dinâmica brasileira”. IPARDES Análise Conjuntural 27(11-12): 8-14.

MACEDO, M. M. \& VIEIRA, V. F. \& MEINERS, W. E. M. A.(2002). "Fases de Desenvolvimento Regional no Brasil e no Paraná: da emergência de um novo modelo de desenvolvimento na economia paranaense". Revista Paranaense de Desenvolvimento 103: 5-22.

MAIA, S. F. (2002). "Efeitos da globalização sobre as vantagens comparativas das exportações do Paraná: metodologias comparadas”. In XL Congresso Brasileiro de Economia e Sociologia Rural - SOBER, Passo Fundo. Anais do RS. CD-ROM.

MARANHO, E. J. (2008). “O Emprego Formal na Indústria de Transformação Paranaense Segundo a Intensidade Tecnológica-1995 a 2007”. Curitiba: IPẢRDES. Nota Técnica.

PASSOS, A. F. \& ANSILIERO, G. \& PAIVA, L. H. (2005). "Mercado de trabalho: evolução recente e perspectivas". Mercado de trabalho - conjuntura e análise. 26: $43-56$.

POCHMANN, M. (2006) Qualidade das ocupações no Brasil. Carta Social e do Trabalho, Cesit, Instituto de Economia, Unicamp, n. 3, jan./abr. URL: http:// www.eco.unicamp.br/cesit/boletim/versãointegral7.pdf. Acesso em: $17 \mathrm{de}$ agosto de 2009.

RAMOS, L. (2007) "Evolução e Realocação Espacial do Emprego Formal- 19952005”. Econômica 9(1): 89-112.

RAMOS, L. (2007). "O Desempenho Recente do Mercado de Trabalho Brasileiro: Tendências, Fatos Estilizados e Padrões Espaciais”. Rio de Janeiro: IPEA Texto para Discussão 1255 .

RAMOS, L. \& FERREIRA, V.(2005). “Padrão Espacial da Evolução do Emprego Formal: 1995-2003”. Rio de Janeiro.Texto para Discussão 977.

SABÓIA, J. (2001). "Descentralização Industrial no Brasil na Década de Noventa: um Processo Dinâmico e Diferenciado Regionalmente”. Nova Economia 11(2):85-121.

SOUZA, C. C. A. (2002). “Análise do Crescimento das Regiões Metropolitanas de Belo Horizonte e Curitiba: um Estudo Comparativo”. In Anais do X Seminário sobre Economia Mineira, Diamantina-MG.

TAVARES, L.P.O. (2005). "São José dos Pinhais no Contexto da recente Industrialização Metropolitana: Reflexos Sócio Espaciais”. Revista Paranaense de Desenvolvimento 108:.33-59.

TRINTIN, J.G. (2006). A Nova Economia Paranaense. 1970-20oo. Maringá: EDUEM. 
FERNANDES, C. B. S. \& CUNHA, M. S. As transformações recentes no mercado de trabalho...

Primeira resposta em: 07 de outubro de 2009 Aceite em: 12 de agosto de 2010 